\title{
Interactions of Consanguinity and Number of Siblings with Childhood Acute Lymphoblastic Leukemia
}

\author{
Ameer Kakaje $\mathbb{D}^{\mathrm{D}},{ }^{1}$ Mohammad Marwan Alhalabi $\left(\mathbb{D},{ }^{1}\right.$ Ayham Ghareeb ${ }^{(\mathbb{D}},{ }^{1}$ Bahjat Karam $(\mathbb{D})$, \\ Bassam Mansour $\mathbb{1}^{1},{ }^{1}$ Bayan Zahra ${ }^{\circ},{ }^{1}$ and Othman Hamdan ${ }^{2}$ \\ ${ }^{1}$ Faculty of Medicine, Damascus University, Damascus, Syria \\ ${ }^{2}$ Haematology Department, Children's University Hospital, Damascus University, Damascus, Syria \\ Correspondence should be addressed to Ameer Kakaje; ameer.kakaje@hotmail.com
}

Received 1 July 2020; Revised 24 September 2020; Accepted 27 November 2020; Published 8 December 2020

Academic Editor: Kailin Xu

Copyright (C) 2020 Ameer Kakaje et al. This is an open access article distributed under the Creative Commons Attribution License, which permits unrestricted use, distribution, and reproduction in any medium, provided the original work is properly cited.

\begin{abstract}
Acute lymphoblastic leukemia (ALL) is a common malignancy in children. Consanguinity has a high prevalence in developing countries and increases the probability of homozygosity for many genes which may affect ALL and its prognosis. We conducted a study to explore the impact of consanguinity and number of siblings on ALL as there are currently no studies to describe this effect. Data were collected from patients' records from the Children's University Hospital of Damascus University, which is the major cancer centre for children in Syria. This study included 193 children with ALL over one year. Number of siblings was not with the French-American-British (FAB) classification, gender, ALL subtype, or risk of ALL children. When comparing consanguinity degrees and complete blood counts at diagnosis, significant contradicting data were found in the third-degree and fourth-degree consanguinity when compared to one another and to not having consanguineous parents as third degree consanguinity was associated with normal platelets but lower WBC counts, and fourth-degree consanguinity was associated with normal haemoglobin levels and WBC counts, but lower platelet counts. Having consanguineous parents was also associated with acquiring ALL at an older age, L2 FAB classification, having a positive family history for malignancies, and not having hepatosplenomegaly $(P<0.05)$. Although L2 is known to be a poor prognosis indicatory, no association was found with consanguinity and risk. Finally, no association was found with ALL subtype or risk $(P>0.05)$. Although consanguinity and number of siblings have affected some variables and prognostic features of childhood ALL, the aetiology is not clear and we need further studies to clarify such an association as this will help in optimising therapy and accurately determine the risk.
\end{abstract}

\section{Introduction}

Consanguineous marriages are defined as two biologically related people joining in marital union. It is a social tradition that is carried on through generations among certain populations and depends on many factors, including religion, culture, and socioeconomic status [1-4]. The most common form is first cousin marriages with a preference for the offspring of the father's brother, and the married couple in this case shares $12.5 \%$ of the genes. Less commonly are double first cousins marriages who share $25 \%$ of the genes and first cousins once removed with $6.25 \%$ of the genes being shared $[5,6]$.

Consanguineous marriages are practiced worldwide with a variation in prevalence; in Europe and North America, it is less than $1 \%$. Meanwhile, this rate can reach up to $50 \%$ of the general population in Arab countries [7]. For instance, the rate can reach up to $56 \%$ in Saudi Arabia $[8,9]$ and $68 \%$ in Egypt [10].

Consanguineous marriages are associated with congenital malformations and recessive gene disorders along with other comorbidities and mortalities [11]. One study in the Middle East found a high prenatal and infant mortality rate with consanguinity [10]. Another study found that $40 \%$ of children with cancers meet the criteria for hereditary cancer susceptibility syndromes [12]. Consanguinity also increases the probability of having homozygosity as it increases the rate of acquiring two copies of the defected recessive alleles from the common ancestor [13]. However, there are other studies that described a reverse association between consanguinity 
and some diseases and cancers [14-16]. This means that consanguinity has complicated interactions that might either increase or decrease susceptibility of certain cancers.

Acute lymphoblastic leukemia (ALL) is the most common diagnosed cancer in children under the age of 15 as it consists around $25 \%$ of the cancers [17]. The astonishing progress of treating childhood cancer came as a result of multimodal and adapted treatment strategies depending on the risk. Around 8 to 9 out of 10 of all children who are properly managed are considered cured [18-20].

Many recessive genes that predispose to ALL and other haematological malignancies can be found more frequently in patients with consanguineous parents such as mismatch repair deficiency syndrome [21]. Meanwhile, although having more siblings was found to predispose to many solid tumours such as anal and stomach cancers, other cancers' risk decreased such as melanoma and endometrial cancer [22]. Acute monocytic leukemia and Hodgkin's lymphoma risks increase in large families, particularly in older siblings [23]. However, there are contradicting data about number of siblings' effect on ALL susceptibly [23-26].

ALL in Syria has distinguished features that may be from the unique environment and exposure to different substances $[26,27]$. This is the first study to evaluate the effect of consanguinity and number of siblings on different variables of childhood ALL as this is important for more personal treatment to maximise the outcomes, mainly in countries with high prevalence of these phenomena.

\section{Materials and Methods}

2.1. Study Design. This is a cross-sectional study conducted in the Children's University Hospital of Damascus University which is the major hospital for haematological disorders in Syria [27]. The data covered the period between $21^{\text {st }}$ August 2017 and $21^{\text {st }}$ August 2018. This hospital is the major paediatric cancer centre among two centres in Syria and provides free healthcare to its patients [27].

2.2. Sampling and Data Collecting. This study included children who had ALL and were 14 years old or younger. ALL was diagnosed by bone marrow aspiration and immune phenotyping. Information was obtained from the hospital's records by the medical examining team at the time of diagnoses, and the information was provided by the child's caregiver(s).

Multiple characteristics of patients such as age, gender, and governorate of origin were also recorded in addition to different characteristics of ALL (Tables 1 and 2). Caregivers were asked by hospital physicians about the biological relationship between both the father and the mother and history of cancers and leukemia in the family.

\subsection{French-American-British (FAB) Classification. FAB clas-} sification is based on morphology and cytochemical staining; it remains effective despite the availability of cytogenetics and can add diagnostic accuracy in some cases [28]. A skilled professor in haematology was involved in determining the
TABLe 1: Characteristics of children with ALL in Syria.

\begin{tabular}{|c|c|c|}
\hline Characteristic & $\begin{array}{c}\text { Count } \\
(n=193)\end{array}$ & $\begin{array}{c}\text { Percentage } \\
(\%)\end{array}$ \\
\hline \multicolumn{3}{|l|}{$\overline{\text { Age }}$} \\
\hline $0-4$ & 70 & 36.3 \\
\hline $5-9$ & 94 & 48.7 \\
\hline $10-14$ & 29 & 15 \\
\hline Missing & 0 & \\
\hline \multicolumn{3}{|l|}{ Gender } \\
\hline Male & 119 & 61.7 \\
\hline Female & 74 & 38.3 \\
\hline Missing & 9 & \\
\hline \multicolumn{3}{|l|}{ Place of living } \\
\hline $\begin{array}{l}\text { Damascus, Rif-Dimashq, and } \\
\text { Aleppo }\end{array}$ & 60 & 32.3 \\
\hline Homs and Hama & 41 & 22 \\
\hline Al-Jazira region & 49 & 26.3 \\
\hline Southern Syria & 18 & 9.6 \\
\hline Syrian coast & 8 & 4.4 \\
\hline Idlib & 10 & 5.4 \\
\hline Missing & 7 & \\
\hline \multicolumn{3}{|l|}{ Mother education level* } \\
\hline Low & 88 & 56.4 \\
\hline Medium & 52 & 33.3 \\
\hline High & 16 & 10.3 \\
\hline Missing & 37 & \\
\hline \multicolumn{3}{|l|}{ Father education level* } \\
\hline Low & 86 & 53.8 \\
\hline Medium & 47 & 29.4 \\
\hline High & 27 & 16.9 \\
\hline Missing & 33 & \\
\hline \multicolumn{3}{|l|}{ Consanguinity } \\
\hline No & 123 & 63.7 \\
\hline Third degree & 58 & 30.1 \\
\hline Fourth degree & 12 & 6.2 \\
\hline Missing & 0 & \\
\hline
\end{tabular}

French-American-British (FAB) classification [29] for each ALL patient whether it was L1 or L2.

2.4. Prognostic Risk. We used Berlin-Frankfurt-Münster (BFM) to determine the risk of ALL patients [30]. However, we merged the two groups of standard and intermediate risks as it will be easier to evaluate and they can overlap, mainly due to lack of genetic testings [27].

The risk was assessed based on age, white blood cell (WBC) count at time of diagnosis, cytogenetic changes such as having Philadelphia chromosome, having medical comorbidities, cerebrospinal fluid (CSF) analysis, testicular involvement, inability to tolerate standard chemotherapy, response to initial therapy, predicted outcome, organomegaly, and lymphadenopathy on examination or chest X-ray (CXR); these were all considered in the determination of each 
TABLE 2: Characteristics of ALL in children in Syria.

\begin{tabular}{|c|c|c|}
\hline Characteristic & Count $(n=193)$ & Percentage (\%) \\
\hline \multicolumn{3}{|l|}{ Main presenting symptom } \\
\hline Constitutional symptoms & 137 & 75.7 \\
\hline Lymphadenopathy & 20 & 11 \\
\hline Hepatosplenomegaly & 5 & 2.8 \\
\hline Bruising & 13 & 6.7 \\
\hline Accidental & 6 & 3.3 \\
\hline Missing & 12 & \\
\hline \multicolumn{3}{|l|}{ Hepatosplenomegaly: } \\
\hline Positive & 133 & 72.7 \\
\hline Negative & 50 & 27.3 \\
\hline Missing & 10 & \\
\hline \multicolumn{3}{|l|}{ Lymphadenopathy } \\
\hline Positive & 158 & $81.9 \%$ \\
\hline Negative & 33 & $17.1 \%$ \\
\hline Missing & 2 & \\
\hline \multicolumn{3}{|l|}{ WBC when diagnosed } \\
\hline 1500 and less & 5 & 2.6 \\
\hline $1500-11500$ & 87 & 45.5 \\
\hline 11500 and above & 99 & 51.8 \\
\hline Missing & 2 & \\
\hline \multicolumn{3}{|l|}{ Haemoglobin levels when diagnosed } \\
\hline $11-16$ & 23 & 12 \\
\hline $11-7$ & 101 & 52.6 \\
\hline 7 and less & 68 & 35.4 \\
\hline Missing & 1 & \\
\hline \multicolumn{3}{|l|}{ Platelets count } \\
\hline More than 400000 & 4 & 2.1 \\
\hline 150000 to 400000 & 21 & 11.1 \\
\hline 150000 to 50000 & 60 & 31.6 \\
\hline 50000 to 20000 & 58 & 30.5 \\
\hline Less than 20000 & 47 & 24.7 \\
\hline Missing & 3 & \\
\hline \multicolumn{3}{|l|}{ CXR } \\
\hline Mediastinal enlargement or lymphadenopathies & 32 & 16.6 \\
\hline Negative & 135 & 80.8 \\
\hline Missing & 26 & \\
\hline \multicolumn{3}{|l|}{ ALL subtype } \\
\hline B ALL & 151 & 79.9 \\
\hline T ALL & 38 & 20.1 \\
\hline Missing & 4 & \\
\hline \multicolumn{3}{|l|}{$\mathrm{CD} 10$} \\
\hline $81 \%$ and more & 97 & 57.1 \\
\hline $21 \%-80 \%$ & 36 & 21.2 \\
\hline $20 \%$ and less & 37 & 21.8 \\
\hline Missing & 23 & \\
\hline \multicolumn{3}{|l|}{ Prognostic risk } \\
\hline Standard & 91 & 51.4 \\
\hline High & 86 & 48.6 \\
\hline
\end{tabular}


TABLE 2: Continued.

\begin{tabular}{lcc}
\hline Characteristic & Count $(n=193)$ & Percentage $(\%)$ \\
\hline Missing & 16 & $62.9 \%$ \\
FAB classification & 90 & $37.1 \%$ \\
L1 & 53 & 50 \\
L2 & 50 \\
Missing & & \\
WBC count of $1500-11500 \times 10^{9}$ cells/L, haemoglobin level of $11-16 \mathrm{~g} / \mathrm{dL}$ and platelet counts of $150000-400000 \times 10^{9}$ cells/L were considered normal.
\end{tabular}

patient's prognosis to conduct a correct chemotherapy protocol [31].

2.5. Other Variables and Definitions. Consanguinity was defined as third-degree relatives (first cousins) and fourthdegree relatives (second cousins, second cousins once removed). Family history was obtained based on the family of the subjects having malignancies in their families regardless of type of cancer or age of presentation. All findings are at time of diagnosis.

Constitutional symptoms were defined as having fever, anorexia, weight loss, or fatigue. CXR was considered positive when it had a mediastinal enlargement or hilar lymphadenopathy. WBC count of $1500-11500 \times 10^{9}$ cells/L, haemoglobin level of $11-16 \mathrm{~g} / \mathrm{dL}$, and platelet counts of 150 $000-400000 \times 10^{9}$ cells $/ \mathrm{L}$ ) were considered normal.

Educational levels were divided into 3 subgroups according to the highest obtained degree. Low educational level included elementary education or lower. Medium educational level included finishing year 9 or year 12. Finally, high educational level included having a university degree or higher. This system is used in Syria as these groups have distinguished features, and it was used previously in many studies [26, 27, 32, 33].

Genetic testings could not be obtained due to unavailability to these tests in many cases in Syria [27]. The issue for proper funding has affected many studies and rendered it difficult to conduct proper diagnostic tools and to carry on studies other than observational $[26,34]$. For easier and more reliable comparisons, only pre-B-ALL and pre-T-ALL were included. We also excluded patients with L2 (Burkitt) leukemia as they may have a confounding viral and/or genetic aetiology that will make the results harder to understand.

2.6. Consent and Ethical Approval. Informed consent was taken before using and publishing their data. The study was approved by the ethic committee of Damascus University.

2.7. Data Analysis. Data were processed using IBM SPSS software version 25 for Windows (SPSS Inc., IL, USA). Chisquare, one-way analysis of variance (ANOVA), and independent $t$-test were performed to determine the statistical significance between the groups. We calculated odds ratio (OR) and the 95\% confidence intervals for the groups using the Mantel-Haenszel test by using the same software. Values of less than 0.05 for the two-tailed $P$ values were considered statistically significant.

\section{Results}

Our sample had 193 ALL patients and their characteristics are demonstrated in Tables 1 and 2. The distribution of children with ALL in each city with their consanguinity degree, age, and gender is shown in Figure 1. Our sample had a mean number of siblings of $4.8 \pm 2.7$.

3.1. Number of Siblings. When comparing number of siblings in ALL children with other variables (Table 3), we found that having a mother of a lower educational level is correlated with having more siblings in ALL patients $(P=0.0002)$. Having more siblings is also associated with ALL diagnosis at an older age $(P=0.0245)$ when comparing age groups 10-14 with 5-9 years, and $P=0.0031$ when comparing age groups 5-9 with 0-4 years. However, when comparing gender, place of living, consanguinity, main presenting symptom, lymphadenopathies, hepatosplenomegaly, haemoglobin level, WBC count, CXR findings, ALL subtype, CD10 levels, prognostic risk, and FAB classification with number of siblings, there was no statistically significant difference $(P>0.05)$. Nevertheless, we found $P=0.079$ when comparing number of siblings with consanguinity overall. The mean number of siblings for patients with consanguineous parents was 5.26 $\pm 2.483(P>0.05)$ when comparing different consanguinity degrees with number of siblings.

3.2. Consanguinity and Complete Blood Count (CBC). Consanguinity rate was $36.3 \%$ with $95 \%$ confidence interval of 29.5\%-42.5\%. Comparing consanguinity with ALL characteristics is demonstrated in (Table 4). Although having parents with third-degree consanguinity was associated with a higher WBC count compared to nonconsanguineous parents ( $P=0.0457$; OR, 1.967; 95\% CI, 1.008-3.839), having parents with fourth-degree consanguinity was correlated with having a normal WBC count $(P=0.0405$; OR, 4.566 ; 95\% CI, 0.64922.222). When comparing patients with parents of thirddegree consanguinity and fourth-degree consanguinity, we found a significant difference in WBC count as it was higher in the third-degree consanguinity group $(P=0.0029$; OR, $0.111 ; 95 \%$ CI, 0.022-0.569), suggesting a different effect from third and fourth degree on WBC count.

Likewise, when comparing third degree-consanguinity and fourth-degree consanguinity with having a normal or abnormal WBC count, we found similar findings as thirddegree consanguinity had an abnormal WBC count more frequently $(P=0.0018 ; \mathrm{OR}, 9.709 ; 95 \% \mathrm{CI}, 1.908-50.000)$. Patients with third-degree consanguinity had higher rates 

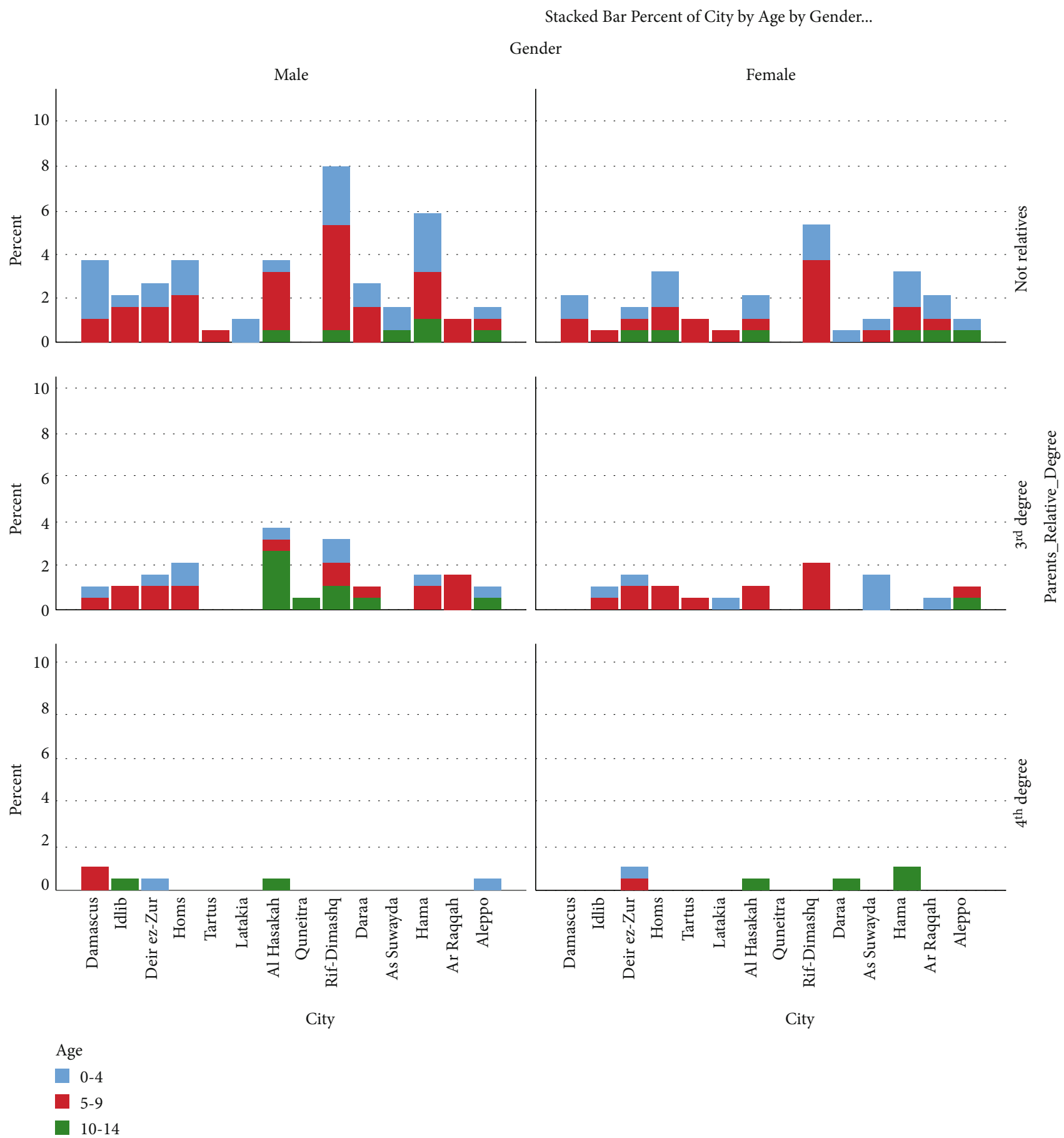

FIGURE 1: Showing percentages of children with ALL in each city with their consanguinity degree, age, and gender.

of abnormal WBC compared to those with no consanguineous parents $(P=0.0303$; OR, 2.063; 95\% CI, 1.065-3.996). In contrast, when patients had parents with fourth-degree consanguinity, they had normal WBC more frequently than those who had parents with no consanguinity $(P=0.0357$; OR, 4.717; 95\% CI, 0.980-22.727).

In ALL patients with low platelet counts (less than 150 $000 \times 10^{9}$ cells/L), when comparing third-degree and fourth-degree consanguinity, there was a statistically signifi- cant difference as the latter was associated with having platelet counts less than $\left(20000 \times 10^{9}\right.$ cells/L) $(P=0.0433)$. Patients with third-degree consanguinity had higher platelet counts (more than $400000 \times 10^{9}$ cells/L) than those with no consanguineous parents $(P=0.0404 ; \mathrm{OR}, 10.500 ; 95 \% \mathrm{CI}$, 0.844-130.663). Finally, patients with third-degree consanguinity had more frequently normal haemoglobin level than abnormal haemoglobin level $(P=0.0485$; OR, 2.433; $95 \%$ CI, 0.986-6.024). 
TABLE 3: Comparing number of siblings in ALL children with other variables.

\begin{tabular}{|c|c|c|}
\hline Characteristic & Mean number of siblings \pm SD & $P$ value \\
\hline \multicolumn{3}{|l|}{ Father education } \\
\hline Low & $5.22 \pm 2.77$ & \multirow{3}{*}{0.100} \\
\hline Medium & $4.21 \pm 2.44$ & \\
\hline High & $4.52 \pm 2.59$ & \\
\hline \multicolumn{3}{|l|}{ Mother education } \\
\hline Low & $5.50 \pm 2.77$ & \multirow{3}{*}{0.0002} \\
\hline Medium & $3.94 \pm 2.16$ & \\
\hline High & $3.31 \pm 2.02$ & \\
\hline \multicolumn{3}{|l|}{ Platelet } \\
\hline Normal & $3.80 \pm 1.85$ & \multirow{2}{*}{ NS } \\
\hline Abnormal & $4.93 \pm 2.80$ & \\
\hline \multicolumn{3}{|l|}{$\mathrm{WBC}$} \\
\hline Normal & $4.84 \pm 2.82$ & \multirow{2}{*}{ NS } \\
\hline Abnormal & $4.79 \pm 2.65$ & \\
\hline \multicolumn{3}{|l|}{ Haemoglobin } \\
\hline Normal & $4.26 \pm 1.74$ & \multirow{2}{*}{ NS } \\
\hline Abnormal & $4.89 \pm 2.83$ & \\
\hline \multicolumn{3}{|l|}{ Consanguinity } \\
\hline Negative & $4.54 \pm 2.81$ & NS \\
\hline All & $5.26 \pm 2.48$ & NS \\
\hline Third degree & $5.25 \pm 2.56$ & \multirow[t]{2}{*}{ NS } \\
\hline Fourth degree & $5.33 \pm 2.19$ & \\
\hline \multicolumn{3}{|l|}{ Age groups } \\
\hline $0-4$ & $3.82 \pm 2.32$ & \multirow{3}{*}{0.0031} \\
\hline $5-9$ & $5.06 \pm 2.72$ & \\
\hline $5-9$ & $5.06 \pm 2.72$ & \\
\hline $10-14$ & $6.39 \pm 2.70$ & 0.0245 \\
\hline
\end{tabular}

3.3. Consanguinity and Age. Having consanguineous parents is correlated with a higher incidence of ALL in the oldest age group (10-14) when compared with the 5-9 age group $(P=0.0242 ;$ OR, 2.619; 95\% CI, 1.117-6.138), especially when comparing fourth-degree consanguineous parents and nonconsanguineous parents $(P=0.0006$; OR, 10.167; $95 \% \mathrm{CI}, 2.228-46.384)$. When comparing age groups, the oldest group (10-14 years) had more parents with fourth-degree consanguinity than the younger group (5-9 years) who had parents with third-degree consanguinity more frequently $(P=0.0223$; OR, 5.455; 95\% CI, 1.159-25.662). In patients aging 10-14 years, male gender was associated with thirddegree consanguinity $(P=0.0332 ; \mathrm{OR}, 10.00 ; 95 \% \mathrm{CI}$, 0.957-100).

3.4. Consanguinity and FAB Classification. Having consanguineous parents is also correlated with having more patients with L1 FAB classification than patients with nonconsanguineous parents ( $P=0.0054$; OR, 2.700; 95\% CI, 1.329-5.487). This was the same when comparing nonconsanguinity with third-degree consanguinity $(P=0.0079 ; \mathrm{OR}, 2.750 ; 95 \%$ CI, 1.290-5.865). Moreover, having consanguineous parents was associated with not having hepatosplenomegaly $(P=0.0161 ;$ OR, 2.242; 95\% CI, 1.153-4.367), similarly to fourth-degree consanguinity $(P=0.0271$; OR, 3.676; $95 \%$ CI, 1.092-12.346).

L2 FAB classification was also found more frequently in male patients with fourth-degree consanguinity $(P=0.0054)$. In patients with L2, ALL incidence was higher among male patients with consanguineous parents $(P=0.0378)$. However, in patients with L1, ALL incidence was higher among female patients with fourth-degree consanguinity $(P=0.0432)$.

3.5. Family History. Having a positive family history was more frequent in children with parents of fourth-degree consanguinity ( $P=0.0387$; OR, 4.333; 95\% CI, 0.975-19.255). The risk of ALL patients, their subtype, and consanguinity degree are demonstrated in Figure 2. In male patients, having consanguineous parents was correlated with having positive family history $(P=0.0446)$ and with having abnormally high platelet counts when diagnosed (higher than $400000 \times 10^{9}$ cells/L, $P=0.0088)$.

3.6. Other Variables. Having consanguineous parents in ALL children was not found to be correlated with ALL subtype, prognostic risk, duration of symptoms before evaluation, CXR findings, parents' educational level, and CD10 $(P>0.05)$. When adjusting for age, gender, subtype, or FAB classification, no other statistically significant differences were found when comparing patients with consanguineous and nonconsanguineous parents.

\section{Discussion}

Consanguinity is noted in many successive generations and children born to a consanguineous family are more likely to marry one of their relatives and carry on this tradition. This pattern is reported in many neighbouring countries to Syria in the Middle East and other parts of Asia such as Turkey [35], Iran [36] and many North African countries. This leads to higher rates of homozygosity for many genes.

In this study, in the 193 ALL patients, $30.1 \%$ had thirddegree consanguineous parents, $6.2 \%$ had fourth-degree consanguineous, and consanguinity overall was $36.3 \%$ which is higher than what was reported in Tehran in ALL children (15.7\%) [37] $(P=0.0001)$, but lower than Saudi Arabia (41.7\%) [12] $(P>0.05)$ and the UAE (80\%) [38] $(P<0.0001)$. We also found that having a mother with a lower educational level is associated with consanguinity which is found in multiple studies [6, 39-41]. However, we did not find this association with the father's educational level in our study.

This study covered many variables of childhood ALL that accompanied consanguinity and number of siblings. As this is the first research to study their effect on different variables, we do not have a rational explanation for many of the findings.

4.1. Childhood ALL and Number of Siblings. The mean number of siblings measured is $4.81 \pm 2.7$ which seemed an 
TABLE 4: Comparison of characteristics of ALL children compared with consanguinity.

\begin{tabular}{|c|c|c|c|c|c|c|c|}
\hline & Nonconsanguineous & $\begin{array}{c}\text { All-degree } \\
\text { consanguinity }\end{array}$ & $\begin{array}{c}P \\
\text { value }^{\mathrm{a}}\end{array}$ & $\begin{array}{c}3^{\text {rd }} \text { degree } \\
\text { consanguinity }\end{array}$ & $\begin{array}{c}P \\
\text { value }^{\mathrm{a}}\end{array}$ & $\begin{array}{c}4^{\text {th }} \text { degree } \\
\text { consanguinity }\end{array}$ & $\begin{array}{c}P \\
\text { value }^{\mathrm{a}}\end{array}$ \\
\hline \multicolumn{8}{|l|}{ Gender } \\
\hline Male & 76 & 43 & \multirow{2}{*}{ NS } & 37 & \multirow{2}{*}{ NS } & 6 & \multirow{2}{*}{ NS } \\
\hline Female & 47 & 27 & & 21 & & 6 & \\
\hline \multicolumn{8}{|l|}{ Subtype } \\
\hline B-cell ALL & 100 & 51 & \multirow{2}{*}{ NS } & 41 & \multirow{2}{*}{ NS } & 10 & \multirow[t]{2}{*}{ NS } \\
\hline T-cell ALL & 21 & 17 & & 15 & & 2 & \\
\hline \multicolumn{8}{|l|}{ Prognosis risk } \\
\hline Low & 64 & 27 & \multirow{2}{*}{ NS } & 22 & \multirow{2}{*}{ NS } & 5 & \multirow{2}{*}{ NS } \\
\hline High & 50 & 36 & & 31 & & 5 & \\
\hline \multicolumn{8}{|c|}{$\begin{array}{l}\text { Duration of symptoms before } \\
\text { evaluation }\end{array}$} \\
\hline 2 weeks or less & 34 & 16 & NS & 16 & NS & 0 & 0.0645 \\
\hline $2-4$ weeks & 38 & 21 & & 17 & & 4 & \\
\hline 4 weeks and more & 48 & 32 & NS & 24 & NS & 8 & 0.0747 \\
\hline \multicolumn{8}{|l|}{$\mathrm{WBC}$} \\
\hline Low & 2 & 3 & NS & 3 & 0.0656 & 0 & NS \\
\hline Normal & 60 & 27 & & 18 & & 9 & \\
\hline High & 61 & 38 & NS & 36 & $0.0457 \mathrm{~b}$ & 2 & $0.0405^{\mathrm{b}}$ \\
\hline \multicolumn{8}{|l|}{ Haemoglobin level } \\
\hline Normal & 11 & 12 & NS & 11 & $0.0515 c$ & 1 & NS \\
\hline Low & 68 & 33 & & 27 & & 6 & \\
\hline Very low & 44 & 24 & NS & 19 & NS & 5 & NS \\
\hline \multicolumn{8}{|l|}{ Platelets count } \\
\hline $400000+$ & 1 & 3 & NS & 3 & 0.0404 & 0 & NS \\
\hline $150000-400000$ & 14 & 7 & NS & 4 & NS & 3 & $\mathrm{NS}^{\mathrm{d}}$ \\
\hline 150000 and less & 108 & 57 & & 48 & & 9 & \\
\hline \multicolumn{8}{|l|}{ CXR } \\
\hline Normal & 92 & 43 & \multirow{2}{*}{ NS } & 35 & & 8 & \multirow{2}{*}{ NS } \\
\hline Abnormal & 20 & 12 & & 10 & & 2 & \\
\hline \multicolumn{8}{|l|}{ Age } \\
\hline $0-$ & 50 & 20 & \multirow[t]{2}{*}{ NS } & 17 & NS & 3 & NS \\
\hline $5-9$ & 61 & 33 & & 30 & & 3 & \\
\hline $10-14$ & 12 & 17 & 0.0242 & 11 & NS & 6 & 0.0006 \\
\hline Mother education lev & & & & & & & \\
\hline Low & 46 & 42 & NS & 34 & NS & 8 & 0.0622 \\
\hline Medium & 35 & 17 & & 16 & & 1 & \\
\hline High & 12 & 4 & NS & 3 & NS & 1 & NS \\
\hline Father education level & & & 100 & & 100 & & 100 \\
\hline Low & 53 & 33 & NS & 26 & & 7 & NS \\
\hline Medium & 27 & 20 & NS & 18 & NS & 2 & NS \\
\hline High & 17 & 10 & NS & 9 & No & 1 & 10 \\
\hline CD 10 & & & & & & & \\
\hline Negative & 20 & 17 & NS & 14 & NS & 3 & NS \\
\hline $20 \%$ and above & 89 & 44 & No & 37 & No & 7 & 10 \\
\hline FAB classification & & & & & & & \\
\hline L1 & 65 & 25 & 00054 & 20 & 00079 & 5 & NS \\
\hline L2 & 26 & 27 & 0.0054 & 22 & 0.0079 & 5 & No \\
\hline Hepatosplenomegaly & & & & & & & \\
\hline
\end{tabular}


TABLE 4: Continued.

\begin{tabular}{|c|c|c|c|c|c|c|c|}
\hline & Nonconsanguineous & $\begin{array}{c}\text { All-degree } \\
\text { consanguinity }\end{array}$ & $\begin{array}{c}P \\
\text { value }^{\mathrm{a}}\end{array}$ & $\begin{array}{c}3^{\text {rd }} \text { degree } \\
\text { consanguinity }\end{array}$ & $\begin{array}{c}P \\
\text { value }^{\mathrm{a}}\end{array}$ & $\begin{array}{c}4^{\text {th }} \text { degree } \\
\text { consanguinity }\end{array}$ & $\begin{array}{c}P \\
\text { value }^{\mathrm{a}}\end{array}$ \\
\hline Negative & 25 & 25 & \multirow{2}{*}{0.0161} & 19 & \multirow{2}{*}{0.0550} & 6 & \multirow{2}{*}{0.0271} \\
\hline Positive & 92 & 41 & & 35 & & 6 & \\
\hline \multicolumn{8}{|c|}{ Lymphadenopathy } \\
\hline Negative & 23 & 10 & \multirow{2}{*}{ NS } & 7 & \multirow{2}{*}{ NS } & 3 & \multirow{2}{*}{ NS } \\
\hline Positive & 100 & 58 & & 49 & & 9 & \\
\hline \multicolumn{8}{|c|}{ Family history } \\
\hline Negative & 104 & 56 & \multirow{2}{*}{0.0811} & 48 & \multirow{2}{*}{ NS } & 8 & \multirow{2}{*}{0.0387} \\
\hline Positive & 9 & 11 & & 8 & & 3 & \\
\hline
\end{tabular}

ALL: acute lymphoblastic leukemia; NS: not significant; FAB: French-American-British classification. Different total subjects between groups occur as some data is missing. ${ }^{a}$ All $P$ values are compared with the nonconsanguineous group. ${ }^{\mathrm{b}}$ The $P$ value when calculated between normal WBC and abnormal is 0.0303 for $3^{\text {rd }}$ degree and 0.0357 for $4^{\text {th }}$ degree consanguinity. ${ }^{\text {c }}$ The $P$ value when calculated between normal haemoglobin and abnormal is $0.0485 .{ }^{\mathrm{d}}$ The $P$ value when calculated between 150000 and 20000 , and 20000 was 0.0156 , WBC count of $1500-11500 \times 10^{9}$ cells/L, haemoglobin level of $11-16 \mathrm{~g} / \mathrm{dL}$, and platelet counts of $150000-400000 \times 10^{9}$ cells/L) were considered normal.

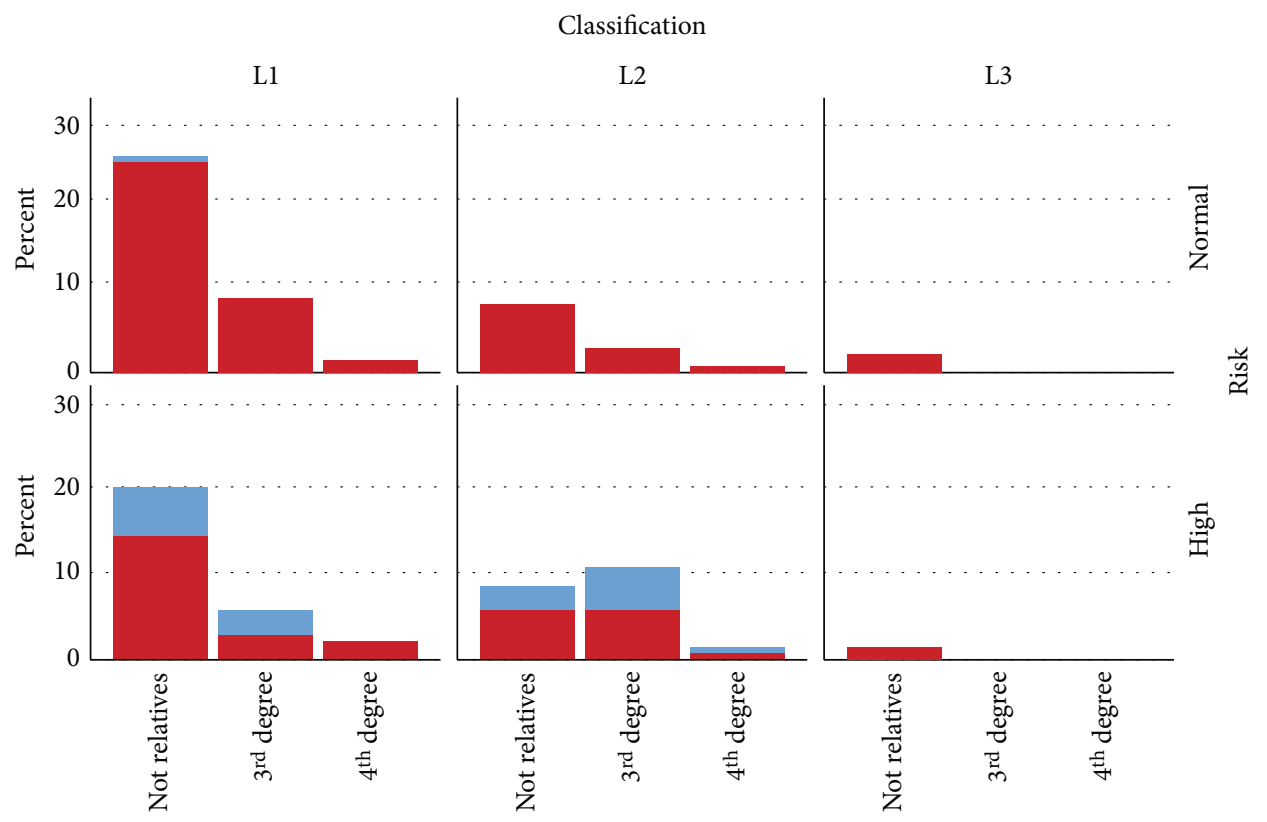

Subtype

T Precurser all

B Precurser all

FIGURE 2: Showing the risk of ALL patients, their subtype, and consanguinity degree.

unusually high number of siblings at time of diagnosis. Lower educational levels in mothers were noted with higher number of siblings. Furthermore, the higher number of siblings was more common among the older population (aged 10-14) when compared to the younger one (0-9) years. However, as having many siblings requires the mother to have a shorter age interval between births of siblings, most of ALL patients in our study had this unusually short interval which may indicate that having many siblings could be indirectly associated with ALL. This contradicts one study which found a significant increase in risk for childhood ALL with long age intervals between births [24]. Another study found that young siblings had lower risk compared to the older ones [23]. However, a study from Denmark did not find a correlation between ALL and age intervals [25]. One case-control study in Syria found no association between number of siblings and ALL [26].

One theory which may explain the increased risk of some cancers when having more siblings is that early-onset and inherited diseases may be demonstrated more frequently in small families due to selection and the limitation of the reproductive period of the parents [22]. In contrast, it was 
speculated that the decreased risk in some cancers such as testicular cancer can be explained by the exposure hypothesis. This hypothesis indicates that in utero exposure to oestrogen will be higher in early pregnancies compared to later ones [22].

We found a slight insignificant increase in number of siblings in patients with consanguineous parents, and there was no difference between different consanguineous groups. This is similar to a study done in Qatar which found a higher fertility in all consanguineous groups and the mean number of pregnancies was also slightly higher in first cousin unions [39]. Risk of ALL was also associated in some studies with high educational level of the mother [25] as they postpone having their first child. However, it was inconclusive if birth order affected ALL. Increased number of siblings in ALL children was correlated with acquiring ALL in older patients (Table 3) $(P<0.05)$. However, it was not correlated with gender, FAB classification, CD10, WBC and platelet counts, haemoglobin CXR findings, ALL subtype, and risk.

4.2. Complete Blood Count and Consanguinity. In Syria, only $2 \%$ of childhood ALL were found to have normal WBC and platelet count [27]. Having conflicting results between patients with third- and fourth-degree consanguinity in parents may reflect overlapping factors being involved. This is especially noted for WBC counts as it is a prognostic indicator and was also suggested to be made a determinant factor for the higher risk group [42].

High frequency of abnormal WBC count was found in patients with third-degree consanguinity, but high frequency of normal WBC count was found in patients with fourthdegree consanguinity; this was reversed when comparing platelet counts as lower platelet counts were found with fourth-degree consanguinity, and normal platelet counts were found more frequently with third-degree consanguinity. Normal haemoglobin levels were also found more frequently with fourth-degree consanguinity.

This all suggests that third-degree consanguinity is correlated with factors that lead to having higher platelets counts but lower WBC counts and that fourth-degree consanguinity is associated with factors that lead to having more normal haemoglobin levels and WBC counts, but lower platelet counts.

4.3. FAB Classification and Consanguinity. L2 in Syria was found to be higher than most studies [27]. L2 was found more frequently in patients with consanguineous parents, especially in third-degree consanguineous parents mainly in males. FAB classification remains an adequate method especially in developing countries as it does not require expensive tests and can be easily applied in most laboratories [27, 43]. Furthermore, L2 was found to have higher relapse rates and poorer survival [44] which means having consanguineous parents may be associated with poorer prognosis.

4.4. Other Factors and Consanguinity. Having fourth-degree consanguinity is correlated with acquiring ALL at an older age 10-14 when compared to third degree or nonconsanguineous parents. Having consanguineous parents of any degree was associated with not having hepatosplenomegaly. Having a positive family history was associated with consanguinity which may indicate a family history of hereditary recessive cancer genes.

Having CD10 marker is a good prognostic indicator, and when CD10 is negative, there is a higher probability of relapse and lower remission rate [45]. However, no statistically significant difference was found when comparing CD10 in patients with consanguineous and nonconsanguineous parents.

Although no direct prognostic risk was associated with either having consanguineous or nonconsanguineous parents, a link was established with having hepatosplenomegaly, having L2, abnormal platelet counts, haemoglobin, and WBC counts at time of diagnosis, higher number of siblings, and lower educational levels in patients of consanguineous parents which all may indicate that consanguinity might worsen the prognosis, either directly or indirectly. However, lower educational level, which is associated with consanguinity and lower education, may be linked to behaviours that may expose children to leukaemogenics [26].

In conclusion, consanguinity and number of siblings have a complex association with ALL. More studies are required to determine the underlying effect and whether there are genes that have not been discovered yet that were involved, or there are other aetiologies or confounding factors that are still unknown.

\section{Data Availability}

Data will be made available upon reasonable request.

\section{Disclosure}

This study was conducted in the Children's University Hospital.

\section{Conflicts of Interest}

We confirm no interest or relationship, financial or otherwise that might be perceived as influencing the objectivity.

\section{Acknowledgments}

We would like to thank Children's University Hospital staff, especially Lina Khouri for the constant support.

\section{References}

[1] S. M. Akrami and Z. Osati, "Is consanguineous marriage religiously encouraged? Islamic and Iranian considerations," Journal of Biosocial Science, vol. 39, no. 2, pp. 313-316, 2007.

[2] A. H. Bittles, "Consanguinity and its relevance to clinical genetics," Clinical Genetics, vol. 60, no. 2, pp. 89-98, 2001.

[3] M. Saadat, "Consanguineous marriages in Iranian folktales," Community Genetics, vol. 10, no. 1, pp. 38-40, 2007.

[4] M. Saadat, "Is consanguineous marriage historically encouraged?," Journal of Biosocial Science, vol. 40, no. 1, pp. 153154, 2008.

[5] P. Harper, Practical Genetic Counselling, 1993. 
[6] A. Bener, Y. M. Abdulrazzaq, L. I. al-Gazali, R. Micallef, A. I. al-Khayat, and T. Gaber, "Consanguinity and associated socio-demographic factors in the United Arab Emirates," Human Heredity, vol. 46, no. 5, pp. 256-264, 1996.

[7] G. O. Tadmouri, P. Nair, T. Obeid, M. T. al Ali, N. al Khaja, and H. A. Hamamy, "Consanguinity and reproductive health among Arabs," Reproductive Health, vol. 6, no. 1, 2009.

[8] A. S. Warsy, M. H. al-Jaser, A. Albdass, S. al-Daihan, and M. Alanazi, "Is consanguinity prevalence decreasing in Saudis?: a study in two generations," African Health Sciences, vol. 14, no. 2, pp. 314-321, 2014.

[9] H. Hamamy, "Consanguineous marriages : preconception consultation in primary health care settings," Journal of Community Genetics, vol. 3, no. 3, pp. 185-192, 2012.

[10] M. M. Mokhtar and M. M. Abdel-Fattah, "Consanguinity and advanced maternal age as risk factors for reproductive losses in Alexandria, Egypt," European journal of epidemiology, vol. 17, no. 6, pp. 559-565, 2001.

[11] L. Jaber, G. J. Halpern, and M. Shohat, "The impact of consanguinity worldwide," Community Genetics, vol. 1, no. 1, pp. 12-17, 1998.

[12] W. Jastaniah, A. Aljefri, M. Ayas et al., "Prevalence of hereditary cancer susceptibility syndromes in children with cancer in a highly consanguineous population," Cancer Epidemiology, vol. 55, pp. 88-95, 2018.

[13] P. S. S. Rao and S. G. Inbaraj, "Inbreeding effects on fetal growth and development," Journal of Medical Genetics, vol. 17, no. 1, pp. 27-33, 1980.

[14] M. Rajaei and M. Saadat, "Association between inbreeding coefficient and susceptibility to HIV-1 infection, a casecontrol study," Germs, vol. 3, no. 4, pp. 122-125, 2013.

[15] M. Saadat and I. Saadat, "Correlation between consanguineous marriages and age-standardized mortality rate due to breast cancer, an ecologic study," Breast Cancer Research and Treatment, vol. 121, no. 3, pp. 795-797, 2010.

[16] M. Saadat, M. Khalili, S. Omidvari, and M. Ansari-Lari, "Parental consanguineous marriages and clinical response to chemotherapy in locally advanced breast cancer patients," Cancer Letters, vol. 302, no. 2, pp. 109-112, 2011.

[17] N. Howlader, A. N., M. Krapcho, and et al.SEER Cancer Statistics Review, "Childhood cancer, National Cancer Institute, 2013, Section 28," 2019, http://seer.cancer.gov/csr/1975_ 2010/results_merged/sect_28_childhood_cancer.pdf..

[18] G. Gatta, G. Zigon, R. Capocaccia et al., "Survival of European children and young adults with cancer diagnosed 1995-2002," European Journal of Cancer, vol. 45, no. 6, pp. 992-1005, 2009.

[19] M. A. Smith, N. L. Seibel, S. F. Altekruse et al., "Outcomes for children and adolescents with cancer: challenges for the twenty-first century," Journal of Clinical Oncology, vol. 28, no. 15, pp. 2625-2634, 2010.

[20] C.-H. Pui, "Toward a total cure for acute lymphoblastic leukemia," Journal of Clinical Oncology, vol. 27, no. 31, pp. 51215123, 2009.

[21] E. Stieglitz and M. L. Loh, "Genetic predispositions to childhood leukemia," Therapeutic Advances in Hematology, vol. 4, no. 4, pp. 270-290, 2013.

[22] A. Altieri and K. Hemminki, "Number of siblings and the risk of solid tumours: a nation-wide study," British Journal of Cancer, vol. 96, no. 11, pp. 1755-1759, 2007.

[23] A. Altieri, "Number of siblings and the risk of lymphoma, leukemia, and myeloma by histopathology," Cancer Epidemiology Biomarkers \& Prevention, vol. 15, no. 7, pp. 1281-1286, 2006.
[24] S. A. Kaye, L. L. Robison, W. A. Smithson, P. Gunderson, F. L. King, and J. P. Neglia, "Maternal reproductive history and birth characteristics in childhood acute lymphoblastic leukemia," Cancer, vol. 68, no. 6, pp. 1351-1355, 1991.

[25] T. Westergaard, M. Frisch, J. B. Pedersen et al., "Birth characteristics, sibling patterns, and acute leukemia risk in childhood: a population-based cohort study," JNCI Journal of the National Cancer Institute, vol. 89, no. 13, pp. 939-947, 1997.

[26] A. Kakaje, M. Alhalabi, A. Ghareeb et al., "Breastfeeding and acute lymphoblastic leukaemia: potential leukemogenesis in children in developing countries," SSRN Electronic Journal, 2020.

[27] A. Kakaje, M. M. Alhalabi, A. Ghareeb et al., "Rates and trends of childhood acute lymphoblastic leukaemia: an epidemiology study," Scientific Reports, vol. 10, no. 1, p. 6756, 2020.

[28] M. U. Sachdeva, J. Ahluwalia, R. Das, N. Varma, and G. Garewal, "Role of FAB classification of acute leukemias in era of immunophenotyping," Indian Journal of Pathology \& Microbiology, vol. 49, no. 4, pp. 524-527, 2006.

[29] M. N. Zafar, "FAB classification of acute lymphoblastic leukaemia (ALL) and its relevance to ALL in Karachi children," The Journal of the Pakistan Medical Association, vol. 35, no. 8, pp. 233-236, 1985.

[30] "Childhood acute lymphoblastic leukemia treatment (PDQ(R)): health professional version," in PDQ Cancer Information Summaries, Bethesda (MD), 2020.

[31] T. Terwilliger and M. Abdul-Hay, "Acute lymphoblastic leukemia: a comprehensive review and 2017 update," Blood Cancer Journal, vol. 7, no. 6, pp. e577-e577, 2017.

[32] A. Kakaje, M. M. Alhalabi, A. Alyousbashi, A. Hamid, and O. Hosam Aldeen, "Allergic rhinitis and its epidemiological distribution in Syria: a high prevalence and additional risks in war time," BioMed Research International, vol. 2020, 9 pages, 2020.

[33] A. Kakaje, M. M. Alhalabi, A. Alyousbashi, A. Hamid, and Y. Mahmoud, "Laryngopharyngeal reflux in war-torn Syria and its association with smoking and other risks: an online cross-sectional population study," BMJ Open, vol. 10, no. 11, p. e041183, 2020.

[34] A. Kakaje, R. Al Zohbi, O. H. Aldeen, L. Makki, A. Alyousbashi, and B. A. Alhaffar, "Mental disorder and PTSD in Syria during wartime: a nationwide crisis.

[35] Ö. M. Alper, H. Erengin, A. E Manguoğlu et al., "Consanguineous marriages in the province of Antalya, Turkey," Annales de Génétique, vol. 47, no. 2, pp. 129-138, 2004.

[36] M. Saadat, M. Ansari-Lari, and D. D. Farhud, "Short report consanguineous marriage in Iran," Annals of Human Biology, vol. 31, no. 2, pp. 263-269, 2009.

[37] M. F. Azim Mehrvar A. A. Hedayati et al., "Epidemiological features of childhood acute leukemia at MAHAK's Pediatric Cancer Treatment and Research Center (MPCTRC)," in BCCR Journal, Tehran, Iran, 2015.

[38] A. Bener, S. Denic, and M. Al-Mazrouei, "Consanguinity and family history of cancer in children with leukemia and lymphomas," Cancer, vol. 92, no. 1, pp. 1-6, 2001.

[39] A. Bener and R. Hussain, "Consanguineous unions and child health in the State of Qatar," Paediatric and Perinatal Epidemiology, vol. 20, no. 5, pp. 372-378, 2006.

[40] S. Sallam, A. Mahfouz, and N. Dabbous, "Reproductive health of married adolescent women in squatter areas in Alexandria, Egypt," 2001. 
[41] H. Tamim, M. Khogali, H. Beydoun, I. Melki, K. Yunis, and National Collaborative Perinatal Neonatal Network, "Consanguinity and apnea of prematurity," American Journal of Epidemiology, vol. 158, no. 10, pp. 942-946, 2003.

[42] G. Vaitkevičienė, E. Forestier, M. Hellebostad et al., "High white blood cell count at diagnosis of childhood acute lymphoblastic leukaemia: biological background and prognostic impact. Results from the NOPHO ALL-92 and ALL-2000 studies," European Journal of Haematology, vol. 86, no. 1, pp. 38-46, 2011.

[43] S. Angelescu et al., "Value of multifaced approach diagnosis and classification of acute leukemias," Maedica (Buchar), vol. 7, no. 3, pp. 254-260, 2012.

[44] D. R. Miller, S. Leikin, V. Albo, H. Sather, and D. Hammond, "Prognostic importance of morphology (FAB classification) in childhood acute lymphoblastic leukaemia (ALL)," British Journal of Haematology, vol. 48, no. 2, pp. 199-206, 1981.

[45] H. Kumar, R. Kumar, R. R. Rao, and J. R. Bhardwaj, “The Cd 10 marker in the investigation of acute lymphoblastic leukaemia," Medical Journal Armed Forces India, vol. 58, no. 1, pp. 27-29, 2002. 